\title{
Analisis TAM Terhadap Faktor-Faktor yang Mempengaruhi Konsumen Menggunakan E-money Indomaret Card di Pontianak
}

\author{
TAM Analysis of Factors That Influence Customers to Use Indomaret Card E-Money in \\ Pontianak
}

\author{
Ana Fitriana ${ }^{1}$, Irawan Wingdes ${ }^{2}$ \\ ${ }^{1,2}$ Jurusan Sistem Informasi, STMIK Pontianak \\ Jl. Merdeka No. 372 Pontianak, Kalimantan Barat \\ Email: ${ }^{1}$ afitriana186@gmail.com, ${ }^{2}$ irawan.wingdes@gmail.com
}

\begin{abstract}
Abstrak
Perkembangan teknologi di berbagai bidang terus berlanjut hingga saat ini dan berdampak terhadap semua industri, termasuk bisnis ritel modern salah satunya Indomaret di Pontianak yang saat ini memfasilitasi transaksi konsumen dengan fitur e-Money. Dengan menggunakan e-Money konsumen bisa memperoleh beberapa keuntungan diantaranya transaksi lebih praktis, mudah, dan cepat, mendapatkan diskon khusus, tidak direpotkan dengan kembalian uang kecil, dan bebas iuran anggota. Tujuan penelitian ini adalah untuk memberikan informasi tentang faktor-faktor yang mempengaruhi minat konsumen Indomaret menggunakan e-Money dan dapat menjadi masukan bagi pihak manajemen Indomaret di Pontianak untuk mengevaluasi efektivitas penggunaan e-Money. Kuesioner dibatasi pada konsumen Indomaret di Pontianak sebagai pengguna e-Money yang berada. Penelitian ini membuktikan bahwa secara parsial ketiga faktor Perceived Usefulness, Perceived Ease of Use, dan Perceived Credibility terbukti mempengaruhi minat konsumen Indomaret menggunakan e-Money. Faktor perceived of usefulness (manfaat) sebagai faktor penarik minat utama konsumen untuk memanfaatkan fasilitas e-Money. Faktor yang menempati urutan kedua adalah faktor perceived ease of use (kemudahan). Sedangkan faktor perceived credibility (keamanan) baru dirasakan oleh konsumen jika e-Money dilengkapi dengan pin dan juga adanya jaminan keamanan selama bertransaksi menggunakan e-Money. Dan secara simultan ketiga faktor tersebut juga memiliki pengaruh yang positif terhadap minat konsumen menggunakan e-Money di Indomaret Pontianak.
\end{abstract}

Kata kunci - behavioral intention, perceived usefulness, perceived ease of use, and perceived credibility

\section{Abstract}

The advancement of technology impacts all industries, including the modern retail industry which similarly done by Indomaret. By using e-Money customers can get benefits such as a effiective and efficient transaction, special discount, have no many cyling, and free of charge. The research purpose of this research is to provide information about factors that affect the customers' interest in using e-Money Indomaret and can become input for the management to evaluate the use of e-Money. The questionnaire was limited to the Pontianak customers and used internet facilities. This research had proven that partially the three factors which are Preceived Usefulness, Preceieved Ease of the Use, and Preceived Credibility influence the interest of the customers to e-Money. The main factor is Perceived of usefullness in attract the customers to use e-Money. The second rank of the factors is perceived ease of use. But the factors of perceived credibility can only be obtained customers when e-Money provide pin. Simultaneously, those three factors have a positive impact through customers' interest in using e-Money of Indomaret at Pontianak.

Keywords--behavioral intention, perceived usefulness, perceived ease of use, and perceived credibility. 


\section{PENDAHULUAN}

Bisnis ritel modern terus meningkatkan kualitas pelayanan dan kenyamanan bagi konsumennya. Termasuk salah satu pemain bisnis ritel modern terbesar dan pertama di Indonesia yaitu Indomaret. Indomaret merupakan minimarket terbesar di Indonesia dan juga waralaba terbesar, dengan total 12.800 gerai per Mei 2016 (60\% milik sendiri dan sisanya 40\% gerai waralaba)[1]. Indomaret merupakan pionir di kelas mini market berdiri pada tahun 1988 dan diwaralabakan tahun 1997. Pola waralaba Indomaret telah teruji dan diakui oleh para investor dengan meningkat tajamnya jumlah gerai waralaba setiap tahunnya. Hal ini diakui pemerintah dengan diperolehnya berbagai penghargaan dengan beragam kategori salah satunya yang terbaru adalah Franchies Market Leader Awards tahun 2016 [2]. Sesuai mottonya "mudah dan hemat", Indomaret terus berupaya memberikan layanan belanja yang nyaman, praktis, mudah dan hemat seiring dengan perkembagan jaman dan kebutuhan masyarakat, diantaranya menyediakan fasilitas Indomaret Card Mandiri yaitu kartu prabayar dengan teknologi smart card contactless. Dengan kartu ini maka pemegang kartu dalam hal ini adalah konsumen Indomaret akan dipermudah dalam bertransaksi dengan cepat dan mudah karena dilakuan secara offline dengan mengurangi nilai uang pada kartu. Hal ini membuktikan keunggulan Indomaret dalam inovasi di berbagai bidang termasuk dalam proses transaksi.

Menurut Bank Indonesia (2014) yang dimaksud dengan Uang Elektronik adalah alat pembayaran yang memenuhi unsur-unsur (1) diterbitkan atas dasar nilai uang yang disetor terlebih dahulu oleh pemegang kepada penerbit; (2) nilai uang disimpan secara elektronik dalam suatu media seperti server atau chip; (3) digunakan sebagai alat pembayaran kepada pedagang yang bukan merupakan penerbit uang elektronik tersebut; dan (4) nilai uang elektronik yang disetor oleh pemegang dan dikelola oleh penerbit bukan merupakan simpanan sebagaimana dimaksud dalam undang-undang yang mengatur mengenai perbankan [3]. E-money diciptakan untuk membantu konsumen agar dapat bertransaksi dengan lebih mudah [4].

Sejak diperkenalkan pada tahun 2008, penggunaan uang elektronik di Indonesia terus mengalami pertumbuhan. tak hanya jumlah uang elektronik yang diterbitkan, nilai dan volume transaksi menggunakan uang elektronik juga meningkat, meskipun saat ini pengunaannya belum sebanyak dengan transaksi cash. Negara Indonesia masih berada dalam fase pengenalan emoney dan sedang berproses untuk diterima oleh masyarakat luas hingga pada akhirnya penggunaan e-money bisa menyeimbangi atau bahkan bisa lebih banyak digunakan dibanding transaksi denga uang cash. Dibandingkan negara-negara ASEAN, penggunaan transaksi pembayaran berbasis elektronik yang dilakukan masyarakat Indonesia relatif masih rendah, sementara dengan kondisi geografi dan jumlah populasi yang cukup besar, masih terdapat potensi yang cukup besar untuk perluasan akses layanan sistem pembayaran di Indonesia. Untuk mendorong peningkatan jumlah penggunaan uang elektronik, Bank Indonesia mencanangkan Gerakan Nasional Non-Tunai (GNNT) dan melakukan sosialisasi-sosialisasi ke berbagai lapisan masyarakat. GNNT ditujukan umtuk meningkatkan kesadaran masyarakat terhadap penggunaan instrument non tunai, sehingga berangsur-angsur terbentuk suatu komunitas atau masyarakat yang lebih menggunakan instrument non tunai (Less Cash Society/LCS) khususnya dalam melakukan transaksi atas kegiatan ekonominya [5].

Dalam upaya mendukung program pemerintah melalui program memasyarakatkan eMoney, salah satunya adalah dengan memasyarakatkan e-Money Indomaret Card. Agar mendapatkan hasil maksimal perlu diketahui terlebih dahulu mengenai faktor-faktor sensitif yang dapat menarik minat konsumen untuk menggunakan emoney secara efektif dan efisien. Sehingga kedepannya bisa memaksimalkan faktor-faktor tersebut untuk menstimulan konsumen supaya tertarik menggunakan e-Money Indomaret Card. Mengingat data yang dijabarkan sebelumnya bahwa tingkat transaksi non-tunai di Indonesia masih rendah.

Berdasarkan penelitian sebelumnya, diketahui bahwa pada teknologi single platform epayment, persepsi resiko merupakan faktor utama yang berpengaruh. Resiko yang dianggap besar dapat mengurangi minat konsumen dalam menggunakan system e-payment tersebut [6] 
Penelitian terdahulu yang membahas hal serupa mengenai e-money memberikan hasil bahwa latar belakang pengusaha dan kemudahan dalam pengggunaan memegang peranan penting dalam menarik minat pengguna emoney di hotel kelas menengah ke bawah di Kenya [7], penelitian terdahulu lainnya mengungkapkan bahwa untuk pengguna e-money di negara maju, persepsi pengguna terhadap manfaat cenderung memainkan peranan penting terhadap minat konsumen menggunakan e-money, selain itu kemudahan penggunaan serta tingkat keamanan yang tinggi juga diharapkan para pengguna e-money di negara maju seperti Singapura, Inggris, Amerika, Australia dan Hongkong [8]. Kemudian pada hasil penelitian mengenai penerimaan emoney terbaru dijumpai bahwa faktor manfaat memegang peranan penting dalam mempengaruhi seorang konsumen menggunakan e-money. Sedangkan penelitian ini dilakukan dengan maksud untuk mengetahui pengaruh faktor-faktor eksternal tersebut (manfaat, kemudahan penggunaan, dan kredibilitas) terhadap penggunaan uang elektronik di kalangan konsumen Indomaret yang dilakukan dengan menguji pengaruh faktor-faktor tersebut menggunakan pendekatan Technology Acceptance Model (TAM). Pendekatan TAM dipilih karena TAM merupakan model yang paling banyak digunakan dalam memprediksi penerimaan teknologi informasi dan telah terbukti menjadi model teoritis yang sangat berguna dalam membantu memahami dan menjelaskan perilaku pemakai dalam implementasi sistem informasi [9].

Berdasarkan latar belakang di atas, maka perumusan masalah dari penelitian ini adalah: "Analisis faktor-faktor yang mempengaruhi konsumen menggunakan e-Money Indomaret Card di Pontianak dengan menggunakan kerangka Technology Acceptance Model (TAM)".

\section{METODE PENELITIAN}

Variabel bebas yang ada pada penelitian ini terdiri dari persepsi manfaat, persepsi kemudahan penggunaan, persepsi kredibilitas dari penggunaan e-Money Indomaret Card. Persepsi manfaat adalah tingkatan dimana pengguna percaya bahwa dengan menggunakan teknologi artau sistem akan meningkatkan kinerja mereka dalam bekerja. Persepsi manfaat diukur dengan beberapa indikator pengukuran yaitu, kecepatan dalam melakukan kegiatan transaksi, kemudahan dalam melakukan kegiatan transaksi, keefektifan dan keefisienan dalam layanan transaksi. Persepsi kemudahan penggunaan diukur dengan menggunakan beberapa indikator antara lain, sistem mudah dipelajari dan penggunaannya fleksibel, sistem dapat mengerjakan dengan mudah apa yang diinginkan oleh pengguna, penggunaan mudah serta pengefisienan waktu dan mudah dioperasikan. Persepsi kredibilitas diukur dengan beberapa indikator yaitu besarnya risiko, keamanan transaksi, kebutuhan transaksi dan jaminan keamanan data pribadi dari Indomaret. Sedangkan variabel terikatnya adalah sikap penggunaan diukur menggunakan indikator pilihan antara lain, keuntungan, keinginan dan kesenangan dalam menggunakan e-Money Indomaret Card.

Skala pengukuran yang digunakan pada penelitian ini adalah: Untuk mengukur PU, PEU, PC, dan BI menggunakan skala Likert berskala 5 dengan skor: sangat setuju $=5$, setuju $=$ 4 , ragu-ragu $=3$, tidak setuju $=2$, sangat tidak setuju $=1$. Kemudian data dianalisis dengan menggunakan SPSS Regresi Berganda (Multiple Regression) guna mengetahui besarnya pengaruh perceived usefulness, perceived ease of use, dan perceived credibility baik secara simultan maupun parsial terhadap behavioural intention konsumen dalam menggunakan emoney Indomaret Card. Adapun rumus Regresi Berganda (Multiple Regression) adalah sebagai berikut [10]:

dimana:

$$
\mathbf{Y}=\mathbf{a}+b_{1} \mathbf{X}_{1}+b_{2} \mathbf{X}_{2}+b_{3} \mathbf{X}_{3}+\mathbf{e}
$$

$\mathrm{Y}=$ Behavioral Intention

$\mathrm{X}_{1} \quad=\quad$ Perceived usefulness

$\mathrm{X}_{2}=$ Perceived ease of use

$\mathrm{X}_{3}=$ Perceived credibility 


$\begin{array}{ll}\mathrm{a} & \text { nilai intercept }(\text { konstant) } \\ \mathrm{b}_{1}, \mathrm{~b}_{2}, \mathrm{~b}_{3} & =\text { Koefisien arah regresi } \\ \mathrm{e} & =\text { Standar error }\end{array}$

Populasi dalam penelitian ini adalah para pengguna e-Money Indomaret Card di Pontianak. Sampel penelitian ini sebanyak 50 orang yang menggunakan e-Money Indomaret Card di Pontianak. Adapun teknik penarikan sampel yang digunakan dalam penelitian ini adalah teknik purposive sampling, dalam teknik ini pemilihan unit sampling dilakukan dengan mempertimbangkan syarat-syarat yang telah ditetapkan sebelumnya [11]. Adapun syarat untuk menjadi sampel pada penelitian ini adalah konsumen Indomaret, domisili pontianak, dan menggunakan e-Money Indomaret Card.

Pada penelitian ini persepsi pengguna terhadap manfaat yang diperoleh dari penggunaan e-Money (Perceived Usefulness), persepsi pengguna terhadap kemudahan menggunakan eMoney (Perceived Ease of Use), dan persepsi pengguna terhadap kredibilitas dari e-Money (Perceived Credibility) diduga berpengaruh secara langsung pada minat menggunakan e-Money (Behavioral Intention). Faktor-faktor lainnya yang dapat mempengaruhi minat menggunakan eMoney Indomaret Card tidak dibahas pada penelitian ini. Pada kerangka TAM berikut digambarkan bentuk hubungan antara variabel bebas dan variabel terikat yang dibahas pada penelitian ini. Supaya dengan mudah diketahui faktor-faktor apa saja yang diteliti. Seperti yang ditampilkan pada gambar 1 berikut:

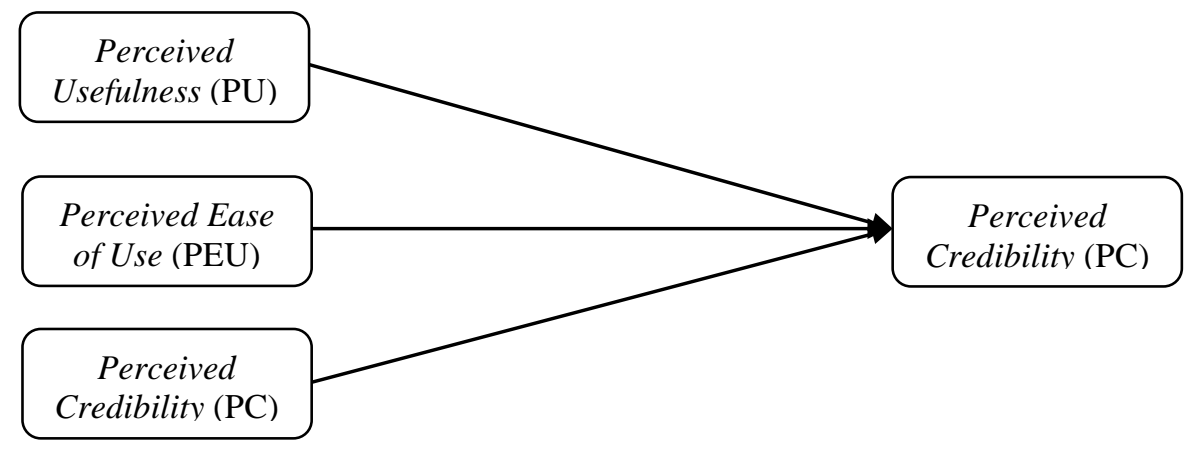

Gambar 1

Kerangka Pemikiran

Untuk menjawab permasalahan tersebut di atas, maka perlu dilakukan uji parsial dan simultan dari variabel bebas yang dilibatkan dalam penelitian ini dalam kaitannya terhadap variabel terikatnya.

\subsection{Uji Parsial (Uji t)}

Untuk menentukan koefisien spesifik yang mana yang tidak sama dengan nol, uji tambahan diperlukan yaitu dengan menggunakan uji t. Uji statistik t pada dasarnya menunjukkan seberapa jauh pengaruh satu variabel independen secara individual dalam menerangkan variasi variabel dependen [12]. Signifikansi koefisien parsial ini memiliki distribusi t dengan derajat kebebasan n-k-1, dan signifikan pada $\alpha=0,05$.

\subsubsection{Persepsi Manfaat terhadap Sikap Penggunaan (Perceived Usefulness toward Behavior Intention)}

Meskipun usaha menurut setiap orang berbeda-beda tetapi pada umumnya untuk menghindari penolakan dari pengguna sistem atas sistem yang dikembangkan, maka sistem harus mudah diaplikasikan oleh pengguna tanpa mengeluarkan usaha yang dianggap memberatkan, dengan begitu pengguna akan mau menggunakan sistem tersebut. Berdasarkan penjelasan tersebut maka hipotesis yang akan diuji adalah: 
H1: Persepsi manfaat berpengaruh positif terhadap sikap penggunaan.

2.1.2 Persepsi Kemudahan Penggunaan terhadap Sikap Penggunaan (Perceived Ease of Use toward Behavior Intention)

Persepsi tentang kemudahan penggunaan sebuah teknologi didefinisikan sebagai suatu ukuran dimana seseorang percaya bahwa, komputer dapat dengan mudah dipahami dan digunakan. Jika seseorang merasa percaya bahwa sistem tersebut berguna maka dia akan bereaksi positif terhadap sistem tersebut dan akan menggunakannya. Sebaliknya, jika seseorang merasa percaya bahwa sistem informasi kurang berguna maka dia tidak akan menggunakannya. Maka hipotesis yang diuji berdasarkan uraian diatas adalah:

H2: Persepsi kemudahan penggunaan berpengaruh positif terhadap sikap penggunaan.

\subsubsection{Persepsi Kredibilitas terhadap Sikap Penggunaan (Perceived Credibility toward Behavior} Intention)

Perceived credibility atau sering disebut sebagai persepsi pengguna terhadap kredibilitas didefinisikan sebagai tingkat dimana seseorang percaya bahwa sistem yang digunakan tetap menjamin keamanan dan privasinya [13]. Apabila seseorang percaya bahwa sebuah sistem dapat membantu segala hal yang dia butuhkan dan dapat menjaga hal-hal yang dianggap penting maka dia akan merasa sistem tersebut dapat diandalkan. Ini berkaitan dengan bagaimana konsumen merasa nyaman dan aman dalam menggunakan e-Money Indomaret Card, jika konsumen merasa hal tersebut dapat terpenuhi maka tentunya rasa puas akan muncul seiring dengan penggunaannya. Maka hipotesis yang diuji berdasarkan uraian diatas adalah:

H3: Persepsi kredibilitas berpengaruh positif terhadap sikap penggunaan

Dasar pengambilan keputusan, dilakukan dengan membandingkan antara nilai $t_{\text {hitung }}$ dengan $t_{\text {tabel: }}$ :

Jika $t_{\text {hitung }}>t_{\text {tabel }}$ maka Ha diterima dan Ho ditolak

Jika $\mathrm{t}_{\text {hitung }}<\mathrm{t}_{\text {tabel }}$ maka Ha ditolak dan Ho diterima

2.2 Uji Simultan (Uji F)

Uji ini bertujuan untuk mengetahui pengaruh variabel bebas dalam penelitian ini, yaitu perceived usefulness (PU), perceived ease of us (PEU), dan perceived credibility $(P C)$, secara bersama-sama terhadap varibel terikat yaitu behavioral intention (BI).

H4: Persepsi manfaat (perceived usefulness/PU), kemudahan penggunaan (perceived ease of $u s / P E U$ ), dan kredibilitas (perceived credibility/PC) berpengaruh positif terhadap sikap penggunaan (behavioral intention/BI)

Dasar pengambilan keputusan, dilakukan dengan membandingkan antara nilai $\mathrm{F}_{\text {hitung }}$ dengan $\mathrm{F}_{\text {tabel }}$ :

Jika $F_{\text {hitung }}>F_{\text {tabel }}$ maka Ha diterima dan Ho ditolak

Jika $\mathrm{F}_{\text {hitung }}<\mathrm{F}_{\text {tabel }}$ maka Ha ditolak dan Ho diterima

Technology Acceptance Model (TAM) dikembangkan oleh Davis pada tahun 1989, sebagai model penerimaan pengguna pada suatu sistem informasi. Sesuai dengan TAM, penggunaan sistem (actual system usage) paling dipengaruhi oleh minat untuk menggunakan (behavioral intentions toward usage). Behavioral intentions toward usage dipengaruhi oleh dua kepercayaan, yaitu persepsi pengguna terhadap manfaat (perceived usefulness) dan persepsi pengguna terhadap kemudahan (perceived ease of use). Perceived usefulness diartikan sebagai 
tingkat dimana seseorang percaya bahwa menggunakan sistem tertentu dapat meningkatkan kinerjanya, dan perceive ease of use diartikan sebagai tingkat dimana seseorang percaya bahwa menggunakan sistem tidak diperlukan usaha apapun (free of effort). Perceive ease of use juga berpengaruh pada perceived usefulness yang dapat diartikan bahwa jika seseorang merasa sistem tersebut mudah digunakan maka sistem tersebut berguna bagi mereka [14].

\section{HASIL DAN PEMBAHASAN}

Sebelum data ini dianalisa regresi lebih lanjut, data ini sudah melewati pengujian validitas dan reliabilitas serta uji asumsi klasik. Dan hasilnya data ini valid, reliabel dan terbebas dari gejala multtikolinieritas, data terdistribusi normal, terbebas dari gejala autokorelasi, dan memenuhi standar heterokedastisitas.

Untuk mengetahui terjadi atau tidaknya multikolinieritas dapat dilihat dari menyatakan bahwa nilai Variance Inflating Factor (VIF) di bawah 10 maka tidak terjadi multikolinieritas (Myer, 1990: 369) dalam thesis Sulistyowati [15]. Kemudian untuk melihat data terdistribusi normal atau tidak bisa menggunakan grafik distribusi histogram dan normal P-P Plot of Regression Standardized Residual. Sedangkan untuk mendeteksi gejala autokorelasi bisa menggunakan uji Durbin-Watson (DW), untuk mengetahui uji heterokedastisitas adalah dengan melihat penyebaran dari varians residual dengan melihat Scatterplot.

Adapun hasil perhitungan regresi bergandanya dapat dilihat dari tabel 1 berikut:

Tabel 1

Hasil Uji Regresi Linier Berganda secara Parsial

\begin{tabular}{|c|c|c|c|c|c|c|c|c|c|c|c|}
\hline & & \multicolumn{10}{|c|}{ Coefficients $^{a}$} \\
\hline \multirow[b]{2}{*}{ Mode } & & \multicolumn{2}{|c|}{$\begin{array}{c}\text { Unstandardized } \\
\text { Coefficients }\end{array}$} & \multirow{2}{*}{$\begin{array}{c}\begin{array}{c}\text { Standardized } \\
\text { Coefficients }\end{array} \\
\text { Beta }\end{array}$} & \multirow[b]{2}{*}{$\mathrm{t}$} & \multirow[b]{2}{*}{ Sig. } & \multicolumn{3}{|c|}{ Correlations } & \multicolumn{2}{|c|}{ Collinearity Statistics } \\
\hline & & B & Std. Error & & & & Zero-order & Partial & Part & Tolerance & VIF \\
\hline 1 & (Constant) & 3.362 & 1.148 & & 2.928 & .005 & & & & & \\
\hline & $\mathrm{PU}$ & 1.131 & .153 & .127 & 2.859 & .395 & .142 & 0.726 & .125 & .958 & 1.044 \\
\hline & PEU & 1.069 & .156 & .066 & 2.443 & .660 & .083 & 0.664 & .064 & .955 & 1.047 \\
\hline & PC & 1.078 & .180 & .066 & 2.433 & .667 & .106 & 0.655 & .063 & .915 & 1.093 \\
\hline
\end{tabular}

a. Dependent Variable: $\mathrm{BI}$

Sumber: Data primer diolah (2017)

Dari hasil perhitungan yang ditunjukkan pada Tabel 1 di atas, diperoleh persamaan regresi sebagai berikut:

$$
Y=3.362+1.131 X_{1}+1.069 X_{2}+1.078 X_{3}+e
$$

3.1 Pengaruh perceived usefulness (X1) terhadap behavioral intention (Y)

Berdasarkan persamaan regresi dan tabel output uji t (Tabel 1), pengaruh variabel perceived usefulness $\left(\mathrm{X}_{1}\right)$ terhadap behavioral intention $(\mathrm{Y})$ dapat disimpulkan bahwa: 
Tabel 2

Pengaruh Perceived Usefulness terhadap Behavioral Intention

\begin{tabular}{|c|c|c|c|}
\hline$\beta$ & $\mathbf{t}_{\text {hitung }}$ & $\mathbf{t}_{\text {tabel }}$ & Korelasi Parsial \\
\hline 1.131 & 2.859 & 2.013 & 0.726 \\
\hline
\end{tabular}

Sumber: Data primer diolah (2017)

Berdasarkan Tabel 2 di atas dapat diambil beberapa kesimpulan sebagai berikut nilai thitung lebih besar dari tabel untuk $\alpha=0,05 \%$ dan derajat bebas $=46$ sebesar 2.013, sehingga dapat diambil keputusan menerima $\mathrm{H}_{\mathrm{a}}$ dan menolak $\mathrm{H}_{\mathrm{o}}$, hal ini berarti berdasarkan hasil penelitian terdapat pengaruh positif yang signifikan dari variabel perceived usefulness terhadap behavioral intention. Sehingga jika nilai variabel perceived usefulness naik sebesar 1 satuan, maka nilai variabel behavioral intention akan meningkat pula sebesar 1.131 dengan asumsi variabel independen lainnya konstan. Nilai korelasi parsial sebesar 1.126 menunjukkan keeratan hubungan perceived usefulness terhadap behavioral intention. Diperoleh besarnya pengaruh parsial perceived usefulness terhadap behavioral intention adalah $(0.726)^{2} \times 100 \%=52.71 \%$.

3.2 Pengaruh perceived ease of use (X2) terhadap behavioral intention (Y)

Berdasarkan persamaan regresi dan tabel output uji $\mathrm{t}$ (Tabel 1), pengaruh variabel perceived ease of use (X2) terhadap behavioral intention $(\mathrm{Y})$ dapat disimpulkan bahwa:

Tabel 3

Pengaruh Perceived Ease of Use terhadap Behavioral Intention

\begin{tabular}{|c|c|c|c|}
\hline$\beta$ & $\mathbf{t}_{\text {hitung }}$ & $\mathbf{t}_{\text {tabel }}$ & Korelasi Parsial \\
\hline 1.069 & 2.443 & 2.013 & 0,664 \\
\hline
\end{tabular}

Sumber: Data primer diolah (2017)

Berdasarkan Tabel 3 di atas dapat diambil beberapa kesimpulan sebagai berikut nilai $t_{\text {hitung }}$ lebih besar dari tabel untuk $\alpha=0,05 \%$ dan derajat bebas $=46$ sebesar 2.013, sehingga dapat diambil keputusan menerima $\mathrm{H}_{\mathrm{a}}$ dan menolak $\mathrm{H}_{\mathrm{o}}$, hal ini berarti berdasarkan hasil penelitian terdapat pengaruh positif yang signifikan dari variabel perceived ease of use terhadap behavioral intention. Sehingga jika nilai variabel perceived ease of use naik sebesar 1 satuan, maka nilai variabel behavioral intention akan meningkat pula sebesar 1.069 dengan asumsi variabel independen lainnya konstan. Nilai korelasi parsial sebesar 0,664 menunjukkan keeratan hubungan perceived ease of use terhadap behavioral intention. Diperoleh besarnya pengaruh parsial perceived ease of use terhadap behavioral intention adalah $(0,664)^{2} \times 100 \%=44.09 \%$.

3.3 Pengaruh perceived credibility (X3) terhadap behavioral intention $(\mathrm{Y})$

Berdasarkan persamaan regresi dan tabel output uji t (Tabel 1), pengaruh variabel perceived credibility (X3) terhadap behavioral intention (Y) dapat disimpulkan bahwa:

Tabel 4

Pengaruh Perceived Credibility terhadap Behavioral Intention

\begin{tabular}{|c|c|c|c|}
\hline$\beta$ & $\mathbf{t}_{\text {hitung }}$ & $\mathbf{t}_{\text {tabel }}$ & Korelasi Parsial \\
\hline 1.078 & 2.433 & 2.013 & 0.655 \\
\hline
\end{tabular}

Sumber: Data primer diolah (2017) 
Berdasarkan Tabel 4 di atas dapat diambil beberapa kesimpulan sebagai berikut nilai $t_{\text {hitung }}$ lebih besar dari $t_{\text {tabel }}$ untuk $\alpha=0,05 \%$ dan derajat bebas $=46$ sebesar 2.013, sehingga dapat diambil keputusan menerima $\mathrm{H}_{\mathrm{a}}$ dan menolak $\mathrm{H}_{0}$, hal ini berarti berdasarkan hasil penelitian terdapat pengaruh positif yang signifikan dari variabel perceived credibility terhadap behavioral intention. Sehingga jika nilai variabel perceived ease of use naik sebesar 1 satuan, maka nilai variabel behavioral intention akan meningkat pula sebesar 1.078 dengan asumsi variabel independen lainnya konstan. Nilai korelasi parsial sebesar 0,655 menunjukkan keeratan hubungan perceived credibility terhadap behavioral intention. Diperoleh besarnya pengaruh parsial perceived perceived credibility terhadap behavioral intention adalah $(0,655)^{2} \times 100 \%=42,90 \%$.

3.4 Pengaruh perceived usefulness (X1),perceived ease of use (X2), perceived credibility (X3) terhadap behavioral intention (Y) secara simultan

Pengujian hipotesis ini berguna untuk mengetahui pengaruh yang signifikan secara bersama-sama atau keseluruhan antara variabel bebas yang meliputi variabel perceived usefulness (X1),perceived ease of use (X2), perceived credibility (X3) terhadap behavioral intention (Y). Dari perhitungan yang telah dilakukan, diperoleh hasil pengujian korelasi berganda secara simultan sebagai berikut:

Tabel 5

Hasil Pengujian Regresi Berganda secara Simultan

\begin{tabular}{|c|c|c|c|c|c|}
\hline $\begin{array}{c}\text { Dependent } \\
\text { Variable }\end{array}$ & $\begin{array}{c}\text { Independent } \\
\text { Variable }\end{array}$ & $\begin{array}{c}\text { Adjusted } \\
\text { R Square }\end{array}$ & F-hit & F-Tabel & Signifikasi \\
\hline $\mathrm{Y}$ & $\mathrm{X}_{1}, \mathrm{X}_{2}, \mathrm{X}_{3}$ & 0.643 & 26.443 & 2,81 & $0,096^{\mathrm{a}}$ \\
\hline
\end{tabular}

Sumber: Data primer diolah (2017)

Berdasarkan Tabel 5 di atas, F-hitung sebesar 26.443 dan F-tabel pada taraf nyata $\alpha=0,05$ sebesar 2.81. Oleh karena F-hitung lebih besar dari F-tabel, atau dapat juga dilihat dari nilai probabilitas sebesar $0,096^{\mathrm{a}}$ yang berada di bawah $\alpha=0,05$, maka dapat disimpulkan bahwa Ho ditolak dan Ha diterima sehingga dapat diartikan bahwa variabel perceived usefulness (X1),perceived ease of use (X2), perceived credibility (X3) berpengaruh positif secara signifikan terhadap behavioral intention $(\mathrm{Y})$.

Sedangkan besarnya pengaruh secara bersama-sama antara variabel perceived usefulness (X1),perceived ease of use (X2), perceived credibility (X3) terhadap behavioral intention ( $\mathrm{Y}$ ) berpengaruh secara signifikan ditunjukkan oleh nilai adjusted $\mathrm{R}^{2}$ sebesar 0.643. Artinya $41.34 \%$ munculnya minat konsumen Indomaret menggunakan e-Money karena dipengaruhi oleh perceived usefulness (X1),perceived ease of use (X2), perceived credibility (X3), sedangkan sisanya 58.66\% merupakan pengaruh faktor lain yang tidak diteliti dalam penelitian ini.

\section{KESIMPULAN}

Secara keseluruhan dapat disimpulkan bahwa faktor yang mempengaruhi minat menggunakan e-Money Indomaret Card (BI) adalah manfaat e-Money Indomaret Card (PU), kemudahan menggunakan e-Money Indomaret Card (PEU), dan kredibilitas e-Money Indomaret Card (PC). Faktor manfaat dari penggunaan e-Money Indomaret Card (PU) memiliki pengaruh yang paling kuat dengan koefisien sebesar 1.131 dibandingkan kemudahan penggunaan eMoney Indomaret Card (PEU) (koefisien sebesar 1.069) dan kredibilitas dari internet banking (PC) (koefisien sebesar 1.078). Dan dari ketiga faktor tadi yang paling mempengaruhi minat nasabah BCA menggunakan internet banking adalah faktor perceived usefullness (manfaat) di dalam menggunakan e-Money Indomaret Card. Setelah faktor perceived usefullness, faktor yang menempati urutan kedua di dalam menarik minat konsumen menggunakan e-Money Indomaret 
Card adalah faktor perceived credibility (keamanan). Hal ini terjadi karena disebabkan konsumen merasakan bahwa penggunaan e-Money Indomaret Card memberikan manfaat yang lebih banyak daripada penggunaan uang tunai, seperti praktis, fleksibel, dan aman.

\section{SARAN}

Penelitian ini dapat menjadi acuan untuk melakukan penelitian dalam mengukur tingkat minat menggunakan e-Money. Adapun saran untuk penelitian yang akan datang adalah menggunakan responden pengguna e-Money dari merchant-merchant lainnya yang menyediakan fasilitas e-Money atau di daerah lain. Sehingga bisa menjadi bahan perbandingan penelitian. Karena penelitian yang dilakukan saat ini ini hanya terbatas pada pengguna e-Money pada Indomaret di Pontianak. Penelitian ini hanya sampai pada faktor-faktor yang mempengaruhi minat menggunakan e-Money sedangkan penelitian yang akan datang dapat meneruskan sampai pada faktor-faktor lain yang mempengaruhi minat masyarakat menggunakan e-Money. Faktor-faktor yang mempengaruhi behavioural intention pada penelitian ini hanya terbatas pada perceived usefulness, perceived ease of use, dan perceived credibility, karena nilai adjusted R2 pada persamaan model regresi di atas menunjukkan koefisien yang tidak sampai $100 \%$, membuktikan bahwa masih terdapat faktor-faktor lain yang mempengaruhi behavioural intention penggunaan e-Money seperti akses e-Money antar merchant yang menyediakan fasilitas e-Money, kemudahan memperoleh e-Money, peningkatan keamanan e-Money seperti penambahan pin pada e-Money, sosialisasi manfaat e-Money kepada masyarakat yang terencana dan berkelanjutan, dan lain-lain.

\section{DAFTAR PUSTAKA}

[1] http://indomaret.co.id/korporat/seputar-indomaret/peduli-dan-berbagi/2014/01/16/geraiindomaret/ [Diakses tanggal 12 Maret 2017 pukul 08.00 WIB]

[2] http://indomaret.co.id/korporat/seputar-indomaret/peduli-dan-berbagi/2014/02/27/awards/ [Diakses tanggal 12 Maret 2017 pukul 08.45 WIB]

[3] Bank Indonesia, Peraturan Bank Indonesia No.11/12/PBI/2009 tentang Cara Uang Elektronik, 2009

[4] Indriastuti, Maya; Wicaksono, Rizki, Herdian, 2014, "Influencers E-Money in Banking Sector”, South East Asia Journal of Contemporary Business, Economics and Law, Vol. 4, Issue 2 ISSN 2289-1560, pp. 10-17, June 2014

[5] http://www.bi.go.id/id/ruang-media/siaran-pers/Pages/sp_165814.aspx [Diakses tanggal 12 Maret 2017 pukul 10.21 WIB]

[6] Chin, L.P. \& Ahmad, Z.A., "Consumers Intention to Use a Single Platform E- Payment System: A Study Among Malaysian Internet and Mobile Banking Users', Journal of Internet Banking and Commerce ISSN: 1204-5357, pp. 112-120, October 2015

[7] Sokobe, Elijah, Ogoti, "Factors Influencing Adoption of Electronic Payment by Small and Medium Hotel Enterprises in Kisii Town, Kisii County, Kenya”, International Journal of Novel Research in Computer Science and Software Engineering, Vol. 2, Issue 2, pp: 5-18, ISSN 2394-7314, May 2015

[8] Indu Niranjan et.al., "Consumer Perceptions in Adopting E-Money in Developed Markets", International Journal of Academic Research, Vol. 4. Issue 4. \& pp. 246-270, November 2016 
[9] Legris, P., Ingham, J., Collerette, P., "Why do people use information technology? A critical review of the technology acceptance model", Information \& Management, Vol. 40, No.3, pp.191-204, January 2003

[10] Sugiyono, Metode Penelitian Bisnis, Bandung: CV. Alfabeta, 2004

[11] Simamora, Bilson, Panduan Riset Perilaku Konsumen, Jakarta: PT. Gramedia Pustaka Utama, 2004

[12] Ghozali, Imam, Aplikasi Multivariate dengan Program SPSS, Semarang: Badan Penerbit Universitas Diponegoro, 2005

[13] Wang, Y.S., Wang, Y.M., Lin, H.H., and Tang, T.I., "Determinants of user acceptance of internet banking: An empirical study", International Journal of Service Industry Management (online journal from Proquest), Vol.14, Iss.5, pg. 501, December 2003

[14] Davis, F.D. "Perceived usefulness, perceived ease of use, and user acceptance of information technology”. MS Quarterly (online), Vol. 13 Iss. 3, pg. 318, July 2005

[15] Sulistiowati, Pengaruh Pelatihan dan Kompensasi terhadap Motivasi Kerja Karyawan Bank KALBAR di Kota Pontianak, Universitas Padjadjaran Bandung, 2005 